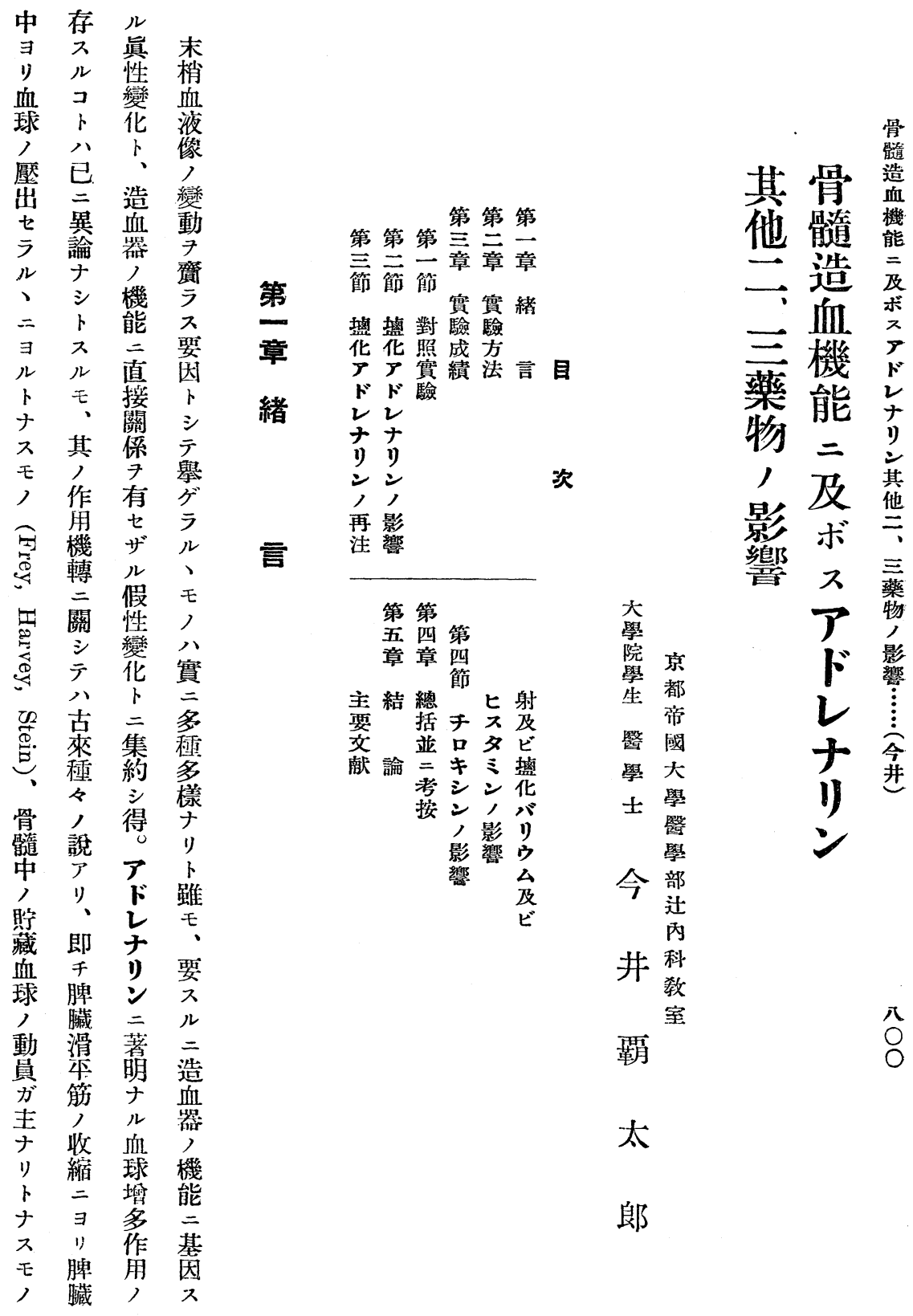




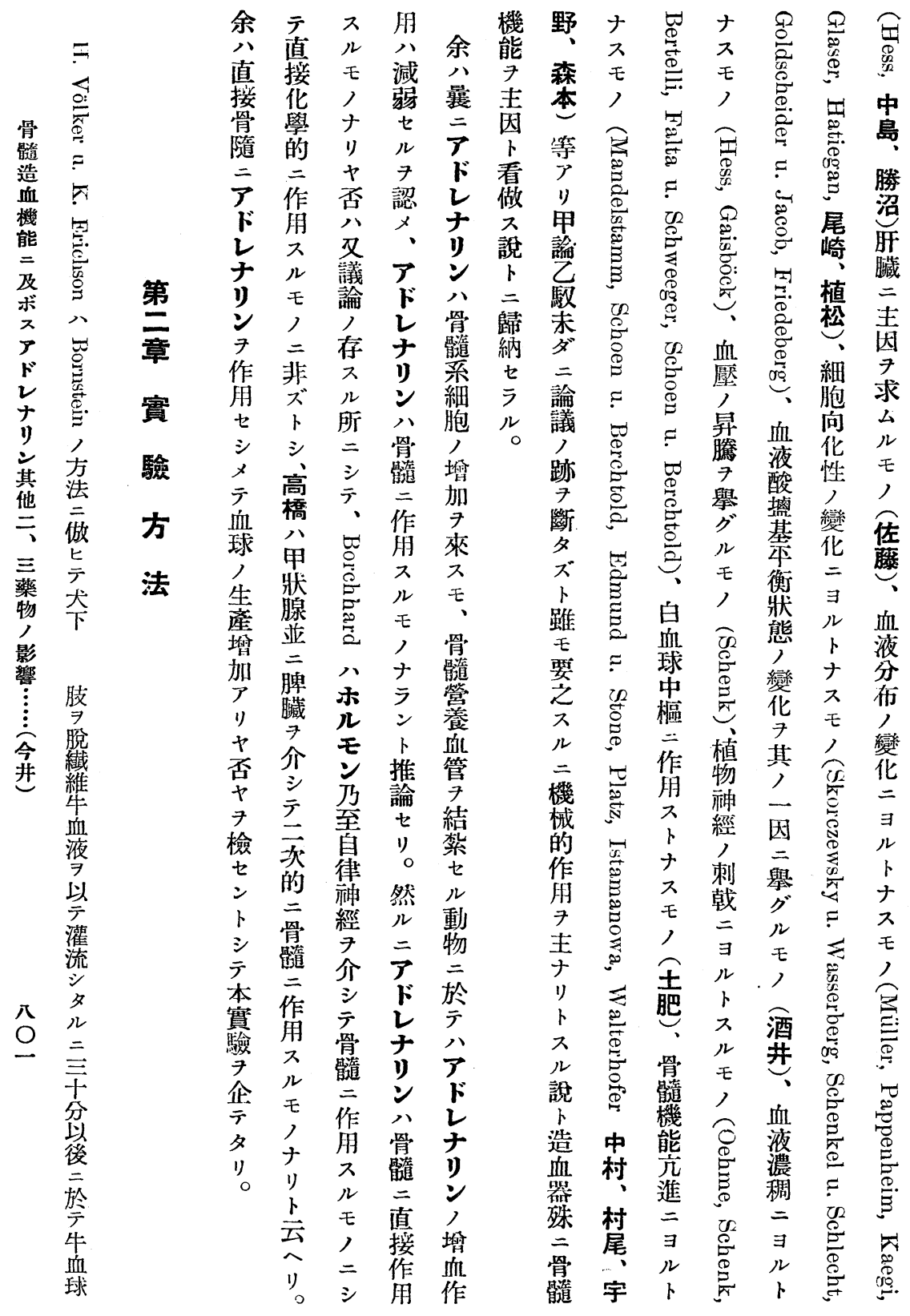




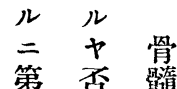

一 $ヤ$ 血

表 及 管

二 ビ 中

示夫

七) 貯

儿動 溜

ガ摇サ

如少儿

㭊、

流 態 血

出 7 球

掖 知 ガ

量

及 ン ソ

含 シ 几

有テ、氐

ル灌

、流 亏

血開 洗

球 始 七

數 後 出

八 -

略 時 ᄂ

々 間夕

不目り

變寻卜

ナリ思

ル 只

7 時 ル

知間、

上 三 後

り至 二

第 間 テ

表 流 流

出 落

液 液

, =

血 䏌

球 血

數 球

檢存

タ 在

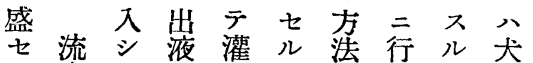

ル出、唀流り 公夜

ス液流明浽更儿認球

ピ 公出卜ぶ三本メ三

ツ試掖ナ灌ル合誌、ヨ骨

グ 驗中り流氏理第骨リ留道

ラ液三夕開液的十髓置造

ス注含儿始 7 厂二, 換 血

三入有後後攝 ラ卷砸サ 機

採前サ試約氏

第 シ ビ、液時市考號市赤及

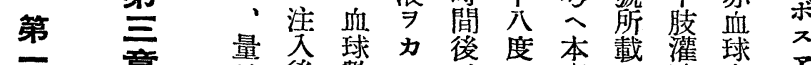
節 章 $\exists$ 後數 二 $三$ 實

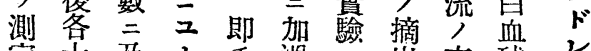

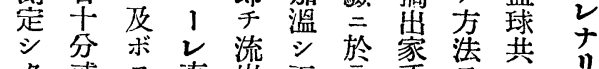
夕或

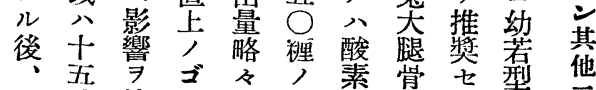

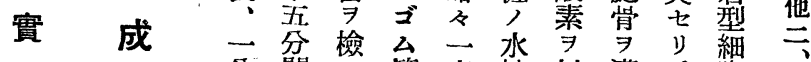

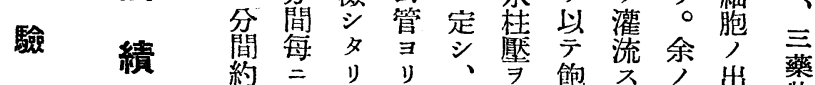

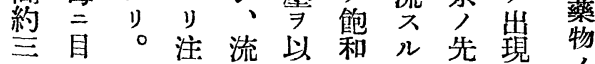

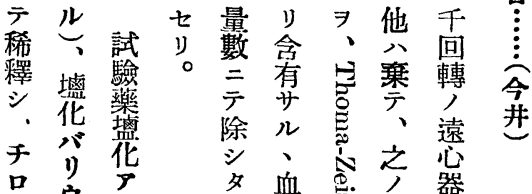

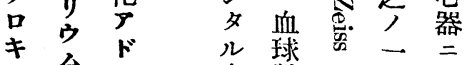

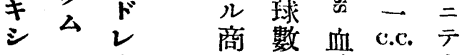

ン +7 球, 十

○ルり流算計琖分

口ルン出算算存間

ツ己气液セ板液遠

シ 共

乙使共 c.c. 0 用 $=$ 㴯

少集七 中此

液 $=$ 公有得液均儿

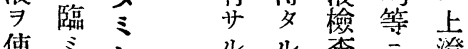

使ミ゙ルル香三登

角り 分、血球樣混液

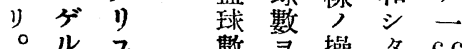

氏

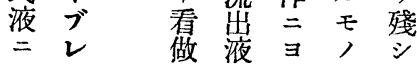


第一表 對

照

\begin{tabular}{|c|c|c|c|c|c|c|}
\hline & \multirow{2}{*}{ 經 過 時 間 } & \multirow{2}{*}{$\begin{array}{c}\text { 各15分間 } \\
=\text { 於ヶ几 } \\
\text { 流出液量 } \\
\text { (c.c.) }\end{array}$} & \multicolumn{2}{|c|}{ 沈澱液 1 c.c. 中， } & \multicolumn{2}{|c|}{ 流出液 I c.c. 中ノ } \\
\hline & & & 白血球數 & 赤血球數 & 白血球數 & 赤血球數 \\
\hline \multirow{4}{*}{1} & $0-15^{\prime}$ & 5.2 & 340 & -730 & 65.4 & 140.4 \\
\hline & $15^{\prime}-30^{\prime}$ & 5.0 & 310 & 700 & 62.0 & 140.0 \\
\hline & $30^{\prime}-45^{\prime}$ & 4.7 & 280 & 680 & 59.6 & 144.6 \\
\hline & $45^{\prime}-60^{\prime}$ & 4.3 & 230 & 620 & 53.4 & 141.1 \\
\hline \multirow{5}{*}{2} & $15^{\prime}$ & 6.1 & 235 & 460 & 38.5 & 75.4 \\
\hline & $30^{\prime}$ & 5.6 & 230 & 420 & 41.0 & 75.0 \\
\hline & $45^{\prime}$ & 5.5 & 200 & 410 & 36.3 & 74.5 \\
\hline & $60^{\prime}$ & 5.2 & 200 & 370 & 38.4 & 71.2 \\
\hline & $75^{\prime}$ & 5.3 & 190 & 370 & 35.8 & 69.8 \\
\hline \multirow{4}{*}{3} & $15^{\prime}$ & 5.8 & 170 & 960 & 30.6 & 165.5 \\
\hline & $30^{\prime}$ & 5.8 & 170 & 950 & 30.6 & 163.8 \\
\hline & $45^{\prime}$ & 5.6 & 150 & 930 & 26.8 & 166.0 \\
\hline & $60^{\prime}$ & 5.3 & 130 & 860 & 24.5 & 162.2 \\
\hline
\end{tabular}

于加否用認

り $九=x$ 前

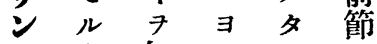

贪 7 血知

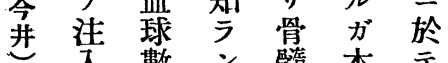

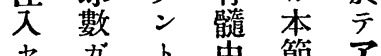

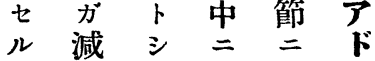

二少示殘於

血三、存等手

球向第 $七 八$

數公舟儿:

公

再 $卜$, 球三

八 ビ ス ア ガ 之り

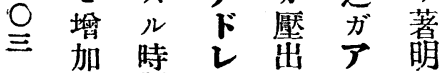

期ナ莳ドナ

示

七於名血

リテ 洼ル り 球

第 再 入 モ, ソ 數

一アヨナ收 㙕

、トリリ縮 加

\section{八倍十液ア}

白㴕萬索余

血 0 倍停 ᄂ

第球主滥歨早

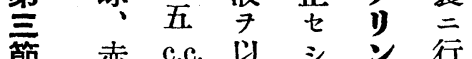
赤 c.c. 以 $三$ 行 節 血 $\exists \bar{x}$,

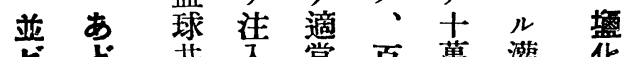
ヒと共入當面萬灌华 三机三窟萬倍流志

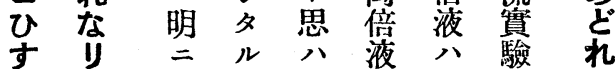

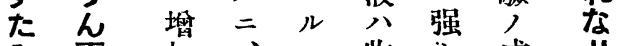

み再加: 收些盛

几注

入出 影灵 7 液》角作見 響 E 認量本稍用儿

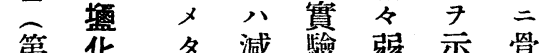
第华夕減驗弱示骨

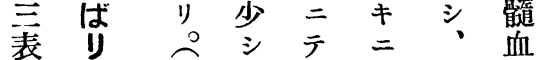

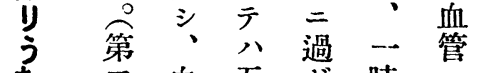

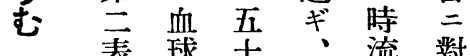

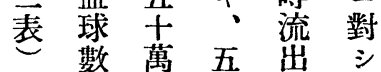


第二表 アドレナリン

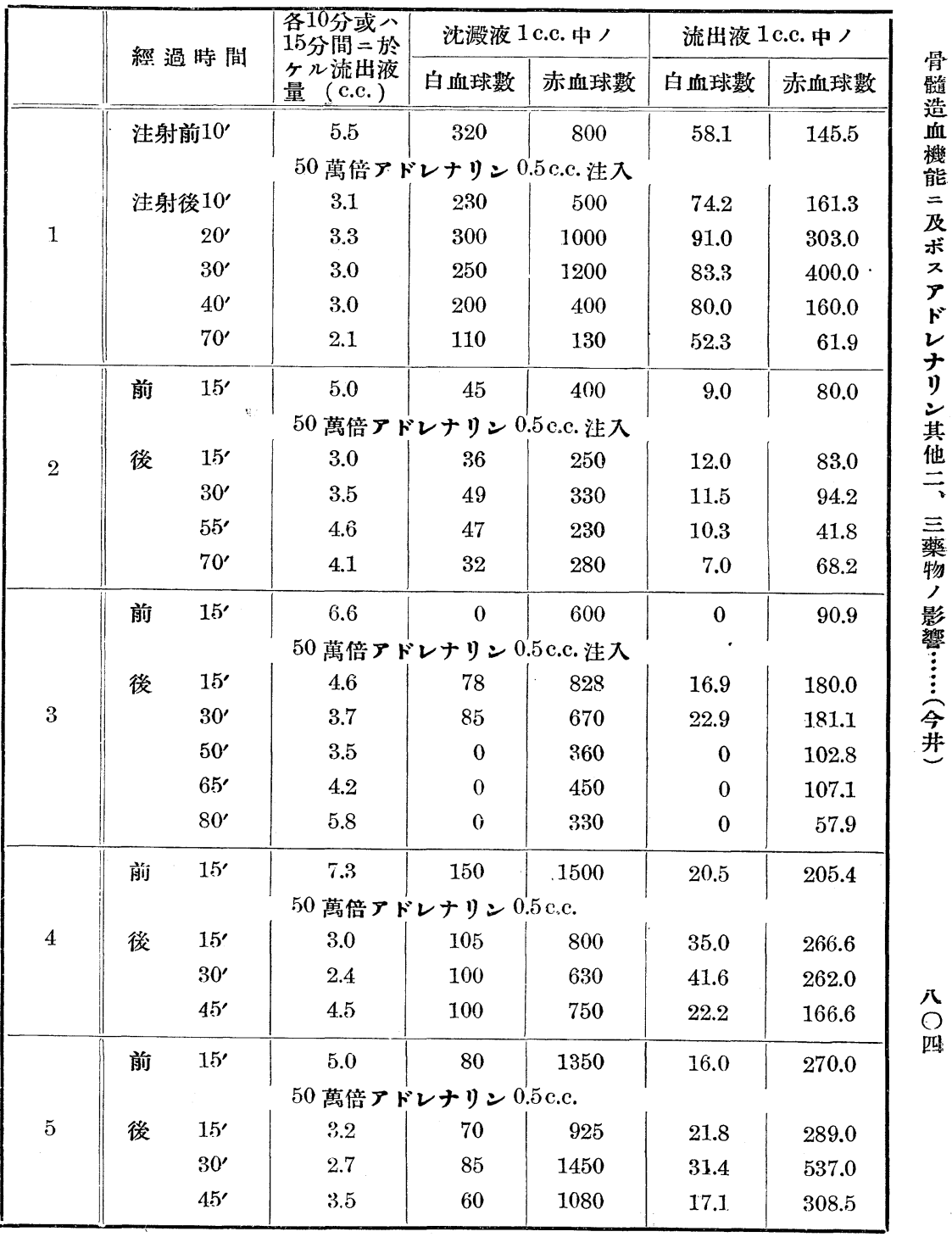




\begin{tabular}{|c|c|c|c|c|c|c|c|}
\hline & \multirow{2}{*}{\multicolumn{2}{|c|}{ 經 過 時間 }} & \multirow{2}{*}{$\begin{array}{c}\text { 各15分間 } \\
=\text { 於ヶ } \\
\text { 流出液量 } \\
\text { (c.c.) }\end{array}$} & \multicolumn{2}{|c|}{ 沈澱液 1 c.c. 中ノ } & \multicolumn{2}{|c|}{ 流出液 1 c.c. 中ノ } \\
\hline & & & & 白组球數 & 赤血球數 & 白血球數 & 赤血球數 \\
\hline \multirow{9}{*}{1} & 前 & & 4.8 & 200 & 2000 & 41.7 & 347.3 \\
\hline & \multicolumn{7}{|c|}{50 薯倍アドレナリン 0.5 c.c. 注入 } \\
\hline & 後 & $15^{\prime}$ & 4.0 & 170 & 2500 & 42.5 & 625.0 \\
\hline & & $30^{\prime}$ & 4.0 & 180 & 2000 & 45.0 & 500.0 \\
\hline & & $45^{\prime}$ & 4.6 & 210 & 2300 & 42.0 & 460.0 \\
\hline & \multicolumn{7}{|c|}{50 萬倍アドレナリン 0.5 c.c. 注入 } \\
\hline & & $15^{\prime}$ & 3.2 & 270 & 2300 & 84.4 & 718.8 \\
\hline & & $30^{\prime}$ & 4.0 & 330 & 2500 & 82.5 & 625.0 \\
\hline & & $50^{\prime}$ & 3.5 & 220 & 1000 & 62.9 & 285.6 \\
\hline \multirow{9}{*}{2} & 前 & $15^{\prime}$ & 5.3 & 120 & 900 & 22.6 & 169.8 \\
\hline & \multicolumn{7}{|c|}{50 萬倍アドレナリン 0.5 c.c. 注入 } \\
\hline & 後 & $15^{\prime}$ & 2.7 & 116 & 680 & 42.9 & 251.7 \\
\hline & & $30^{\prime}$ & 3.2 & 116 & 750 & 36.2 & 234.3 \\
\hline & & $45^{\prime}$ & 4.0 & 123 & 700 & 30.7 & 175.0 \\
\hline & \multicolumn{7}{|c|}{50 萬倍アドレナリン 0.5 c.c. 注入 } \\
\hline & & $15^{\prime}$ & 2.0 & 95 & 520 & 47.5 & 260.0 \\
\hline & & $30^{\prime}$ & 1.7 & 83 & 480 & 48.8 & 282.3 \\
\hline & & $45^{\prime}$ & 2.8 & 70 & 480 & 29.1 & 171.4 \\
\hline \multirow{7}{*}{3} & 前 & $10^{\prime}$ & 5.6 & 94 & 1510 & 16.7 & 269.8 \\
\hline & \multicolumn{7}{|c|}{$1 \%$ 盛化バリウム 0.5 c.c. 注入 } \\
\hline & 後 & $10^{\prime}$ & 4.6 & 81 & 1230 & 17.5 & 267.3 \\
\hline & & $20^{\prime}$ & 3.7 & 50 & 930 & 13.5 & 167.8 \\
\hline & & $30^{\prime}$ & 3.5 & 60 & 950 & 17.1 & 260.1 \\
\hline & & $40^{\prime}$ & 3.2 & 54 & 900 & 16.8 & 281.2 \\
\hline & & $60^{\prime}$ & 4.5 & 45 & 500 & 10.0 & 111.1 \\
\hline \multirow{5}{*}{4} & 前 & $15^{\prime}$ & 9.2 & 160 & 900 & 19.2 & 97.8 \\
\hline & \multicolumn{7}{|c|}{$1 \%$ 墭化バリウム 0.5 c.c. 注入 } \\
\hline & 後 & $15^{\prime}$ & 7.1 & 140 & 700 & 18.3 & 98.5 \\
\hline & & $30^{\prime}$ & 7.5 & 150 & 740 & 20.0 & 98.6 \\
\hline & & $45^{\prime}$ & 7.3 & 138 & 700 & 18.9 & 95.9 \\
\hline
\end{tabular}




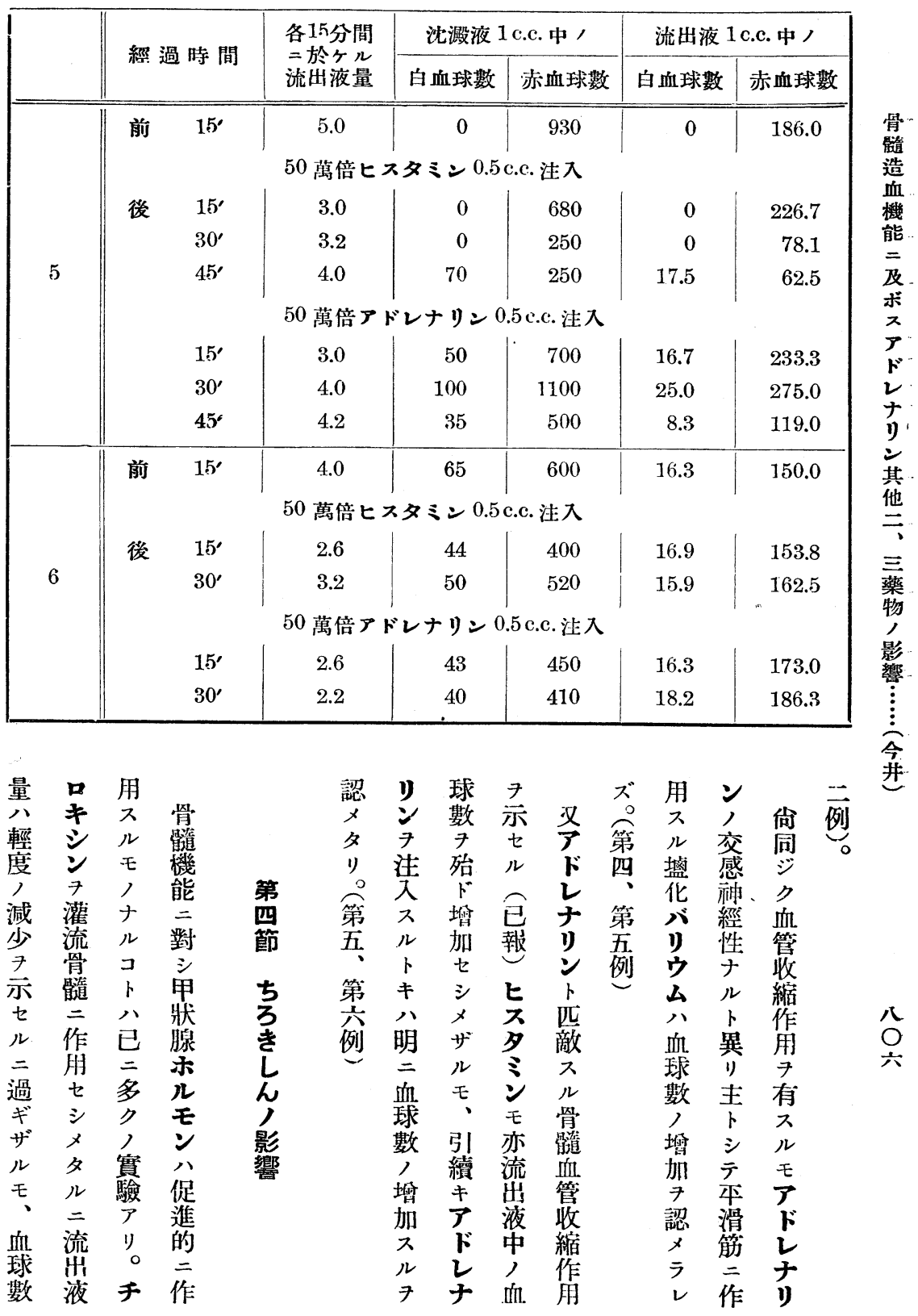


第 四表

\begin{tabular}{|c|c|c|c|c|c|c|c|}
\hline & \multirow{2}{*}{\multicolumn{2}{|c|}{ 經 過 時間 }} & \multirow{2}{*}{$\begin{array}{c}\text { 流出液量 } \\
\text { 各15分間 } \\
(\text { c.c. })\end{array}$} & \multicolumn{2}{|c|}{ 沈澱液 1 c.c. 中ノ } & \multicolumn{2}{|c|}{ 流出液 1 c.c. 中， } \\
\hline & & & & 白血球數 & 赤血球數 & 白血球數 & 赤血球數 \\
\hline \multirow{6}{*}{1} & 前 & $15^{\prime}$ & 3.3 & 42 & 125 & 12.7 & 37.0 \\
\hline & \multicolumn{7}{|c|}{ チロキシン 0.5c.c. 注入 } \\
\hline & 後 & $15^{\prime}$ & 3.5 & 50 & 140 & 14.3 & 40.0 \\
\hline & & $30^{\prime}$ & 3.4 & 50 & 130 & 14.7 & 44.1 \\
\hline & & $45^{\prime}$ & 3.6 & 60 & 133 & 16.6 & 36.9 \\
\hline & & $60^{\prime}$ & 3.6 & 50 & 110 & 13.8 & 30.6 \\
\hline \multirow{5}{*}{2} & 前 & $15^{\prime}$ & 8.2 & 50 & 300 & 6.1 & 36.5 \\
\hline & \multicolumn{7}{|c|}{ チロキシン $\quad 0.5$ c.c. 注入 } \\
\hline & 後 & $15^{\prime}$ & 7.5 & 77 & 280 & 10.3 & 37.4 \\
\hline & & $30^{\prime}$ & 7.2 & 80 & 280 & 11.1 & 38.8 \\
\hline & & $45^{\prime}$ & 7.3 & 50 & 200 & 7.9 & 33.3 \\
\hline \multirow{5}{*}{3} & 前 & $15^{\prime}$ & 3.6 & 60 & 278 & 16.7 & 77.2 \\
\hline & \multicolumn{7}{|c|}{ チロキシン 05 c.c.注入 } \\
\hline & 後 & $15^{\prime}$ & 3.1 & 90 & 250 & 28.9 & 80.6 \\
\hline & & $30^{\prime}$ & 3.4 & 75 & 270 & 22.1 & 79.4 \\
\hline & & $45^{\prime}$ & 2.8 & 70 & 220 & 18.9 & 78.5 \\
\hline
\end{tabular}

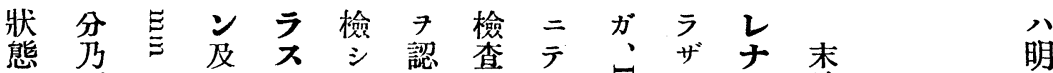
チ至ハ ビ テ ア 認云大 多 ン ド、、、

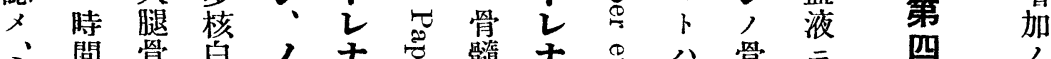

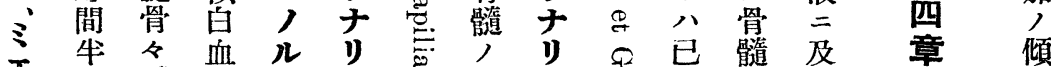

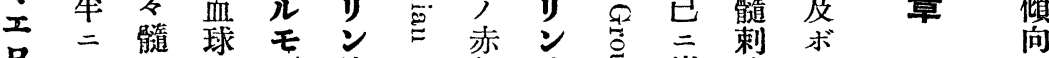

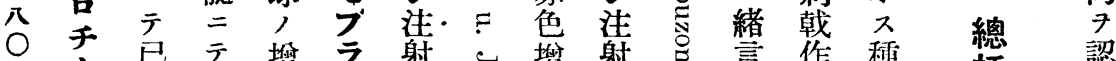

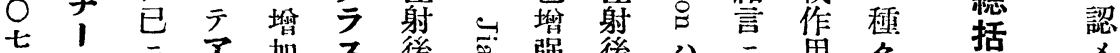
テ 骨

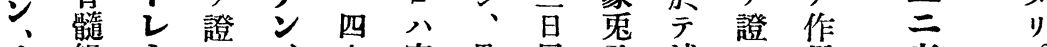

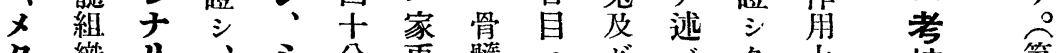

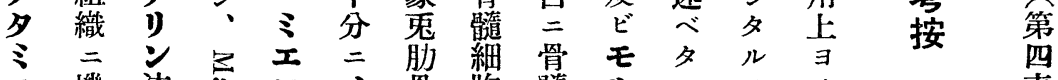

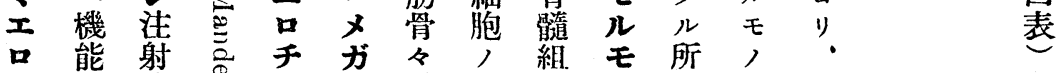
千態射总 チ ।進七产 テ ブ 
栗 三卜並 $尹=$ 四出愺又吕好云テ

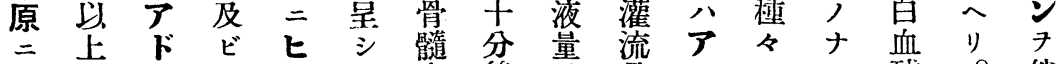

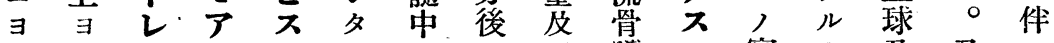

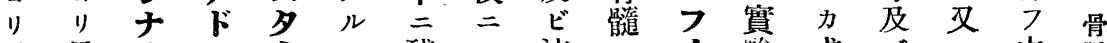

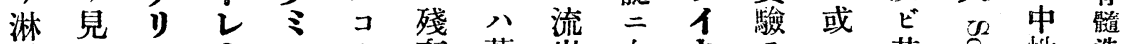
巴ルンナント存著出血キ丹其名性造

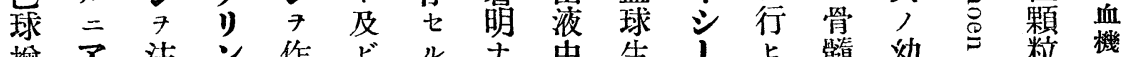
增 ヶ $七$ 匹

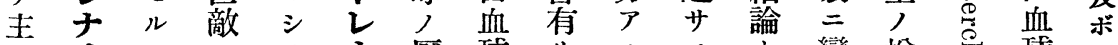

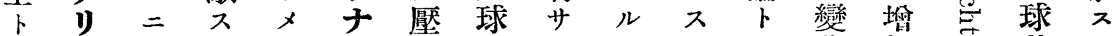

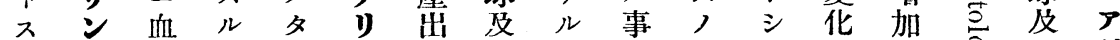

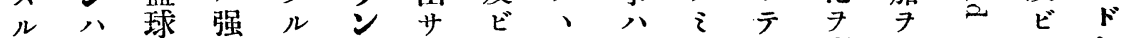
白骨數力時占 $九$ 赤血已

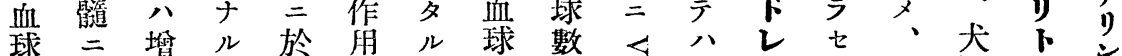

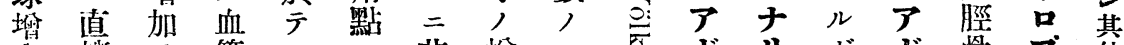
多 接 7 管 公公債

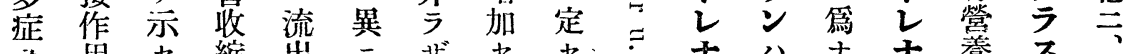
來用七縮 出

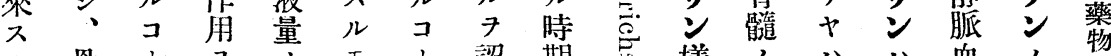
コ骨卜子壬 卜骺二示減: 八 子造 $\exists$ 少摘、 、於

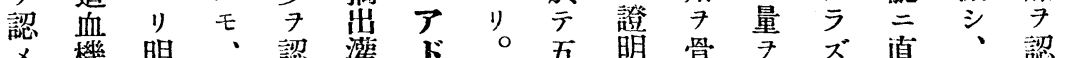
ラ機 明 ‘ 認灌

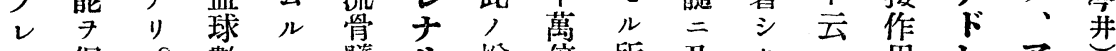

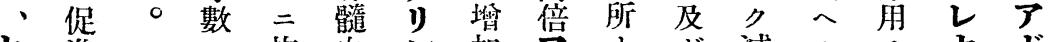

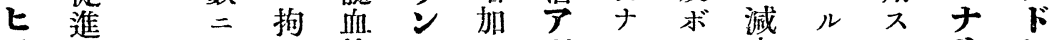
ス采

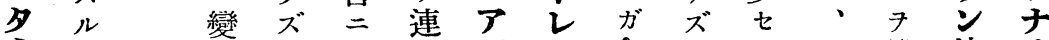
モ 化流對續 ゙゙ナ余上 シ 吸證注り

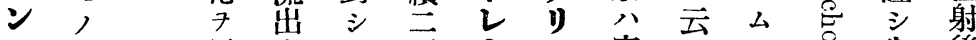

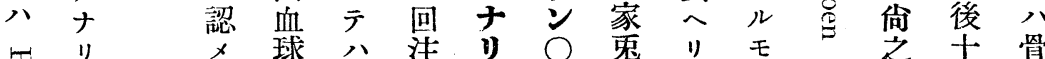

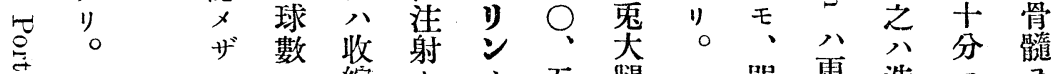

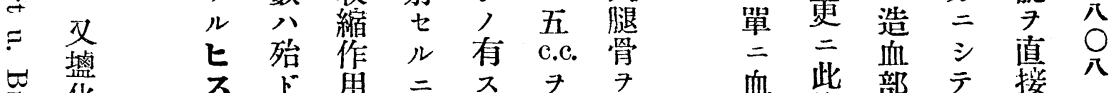

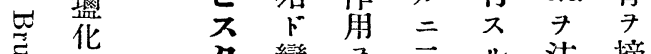
多變 二 二 洼 摘

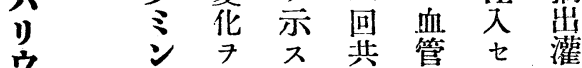
当

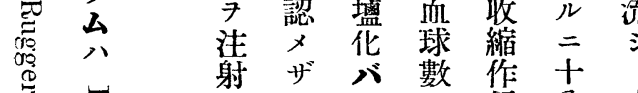
品 射ザ バ數 作十、

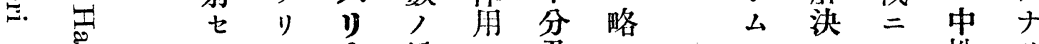
ヨ峦 後 


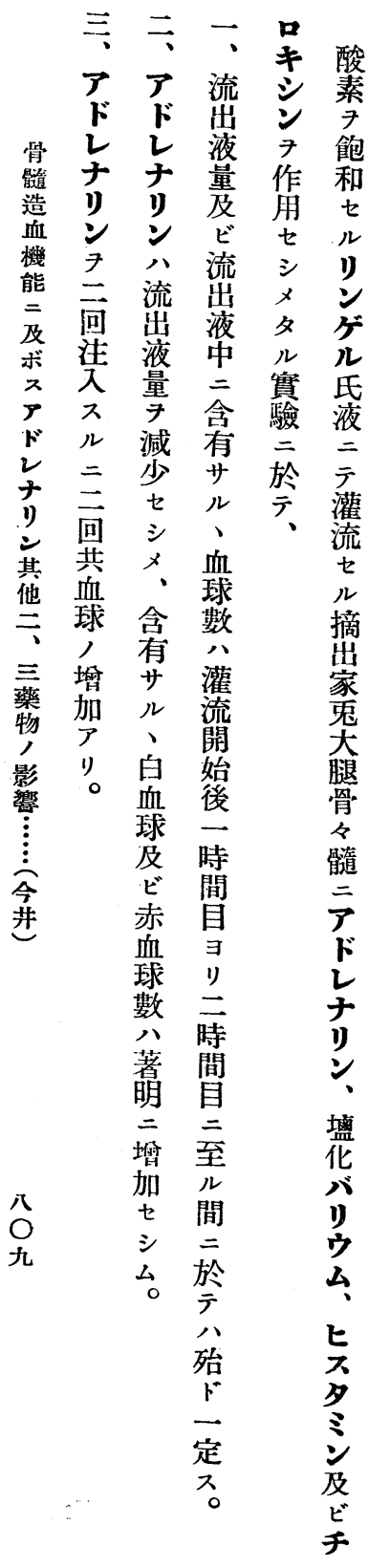

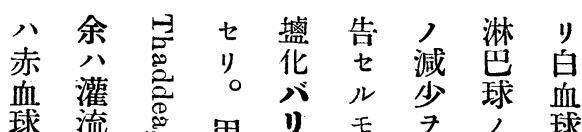

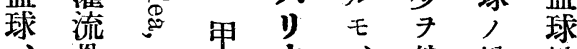
感中牀方件增䅨 夏膸尾腺公余白加多 球于橫示脾成血中認 共口开モ贜 䋶 球性メ

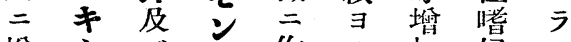
等增 シ ビ 二作り加好レ

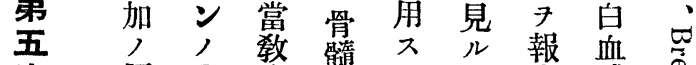

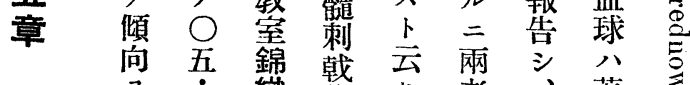

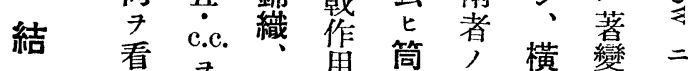

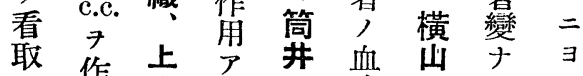

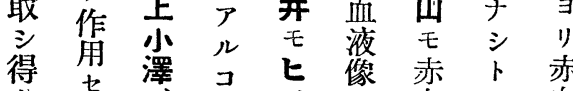
論

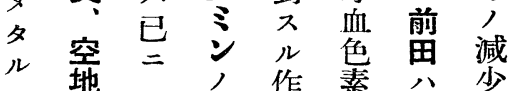
二地血作素少

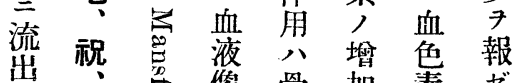

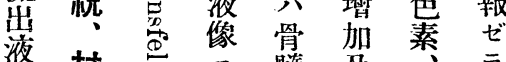

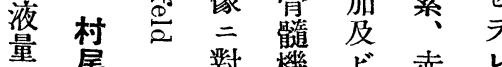

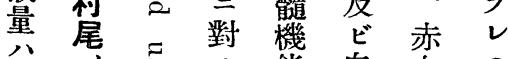

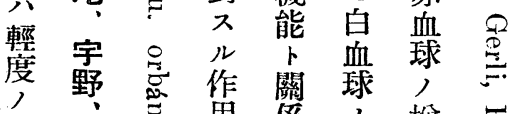

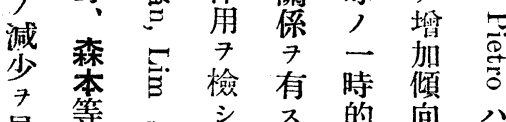

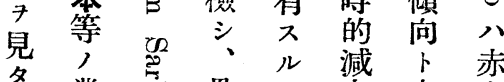
几業㐭骨毛省中血

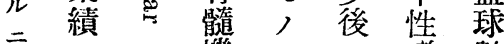

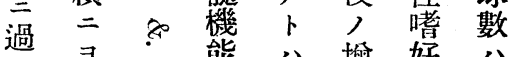
過寻能公㒄好公

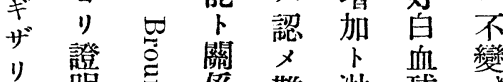

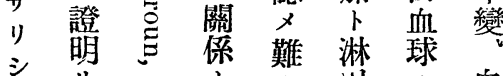

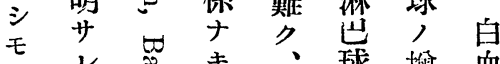

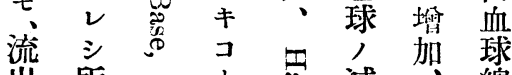

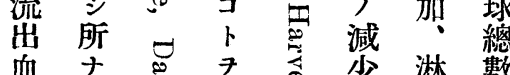

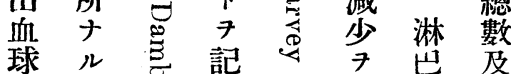

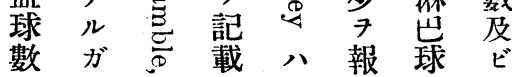




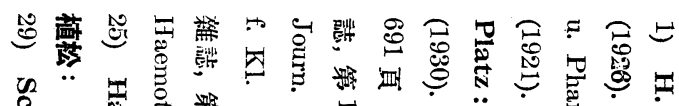

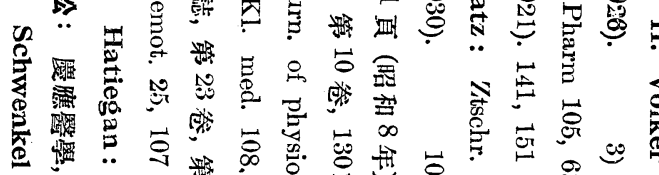

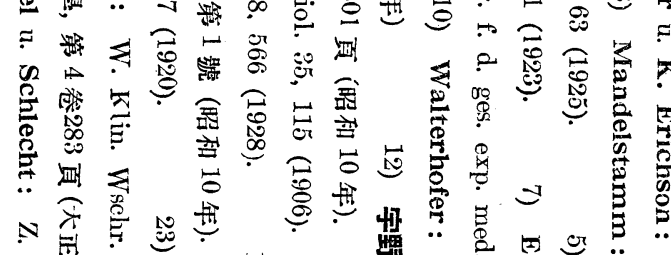

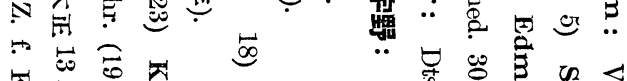

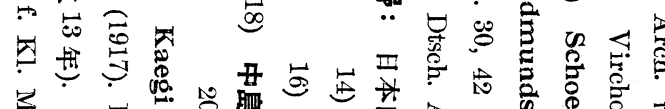

总

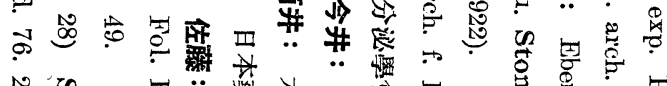

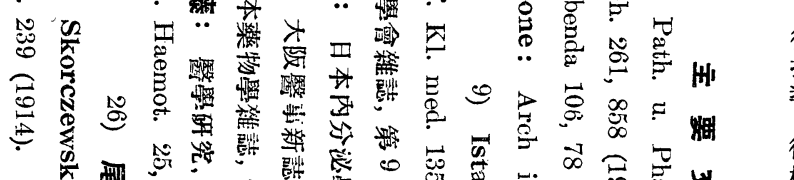

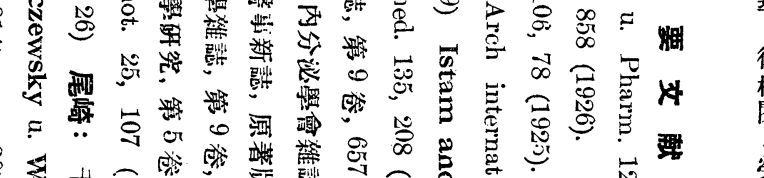

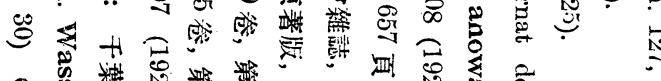

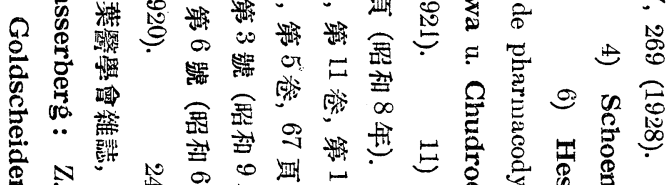

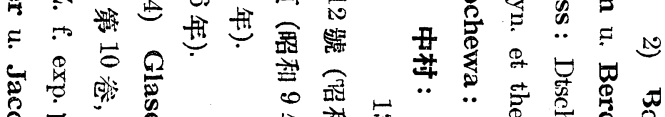

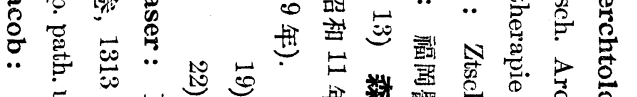

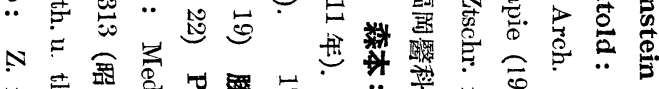

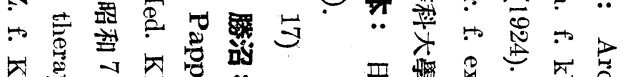

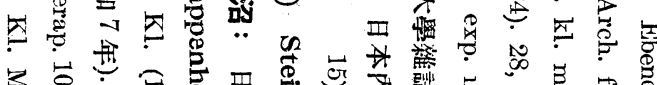

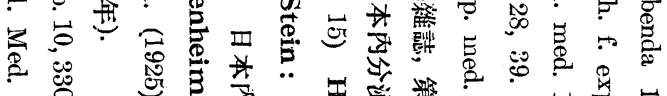

心

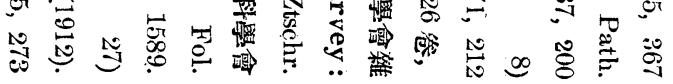

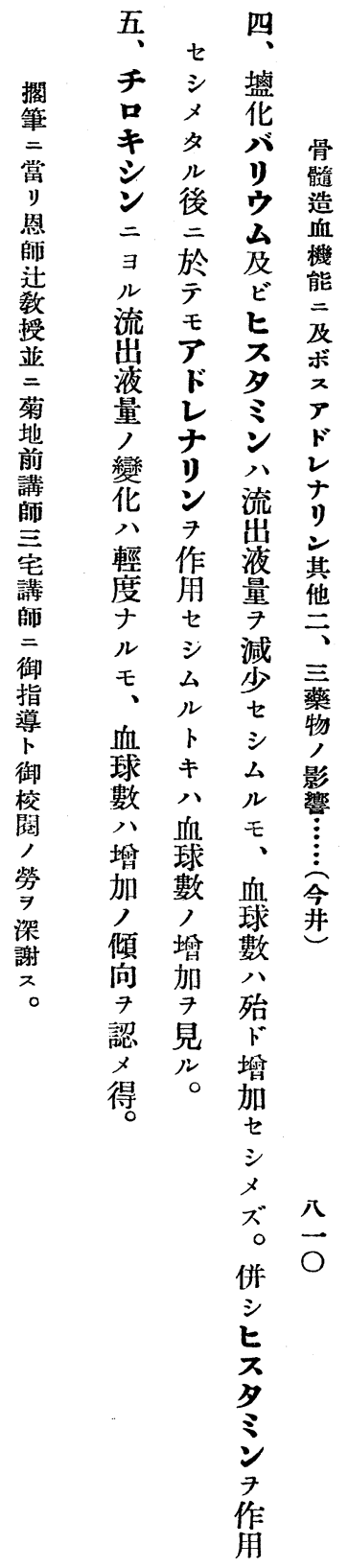




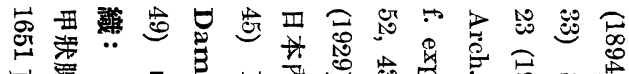

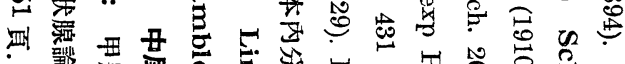

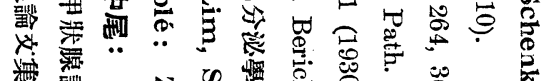

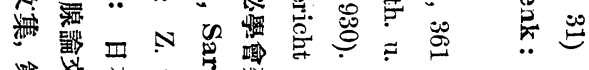

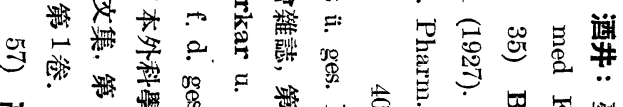

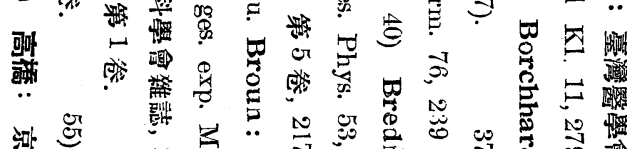

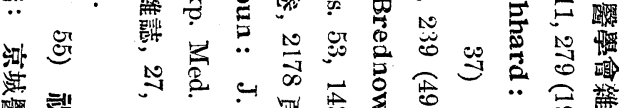

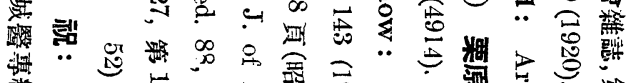

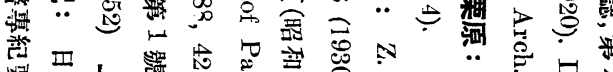

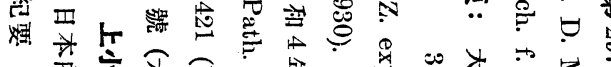

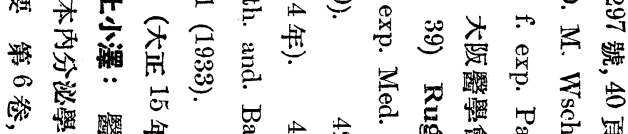

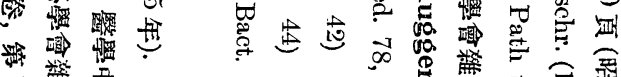

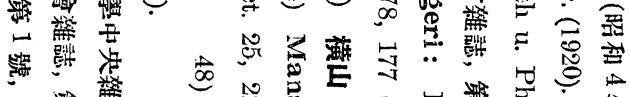

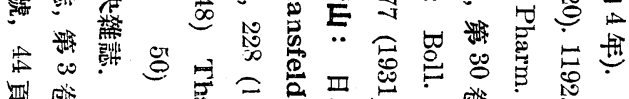

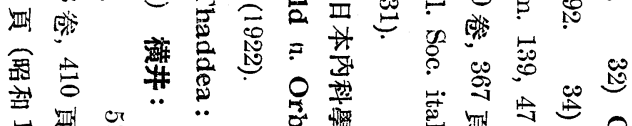

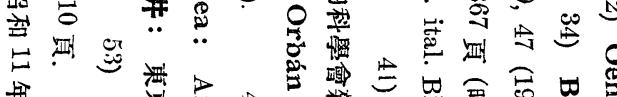

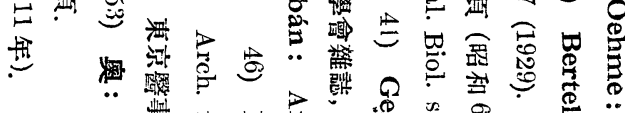

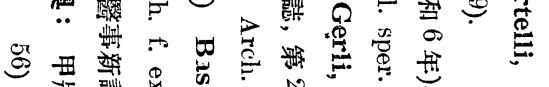

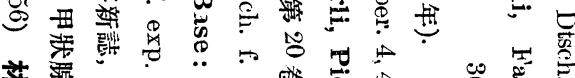

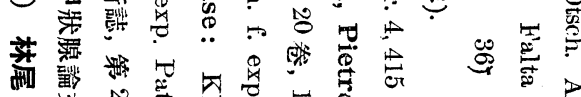

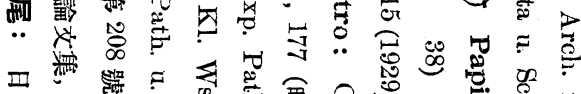

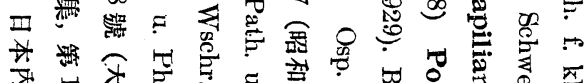

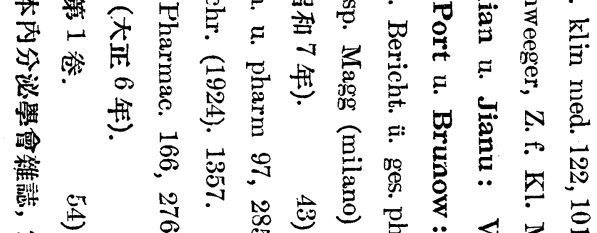

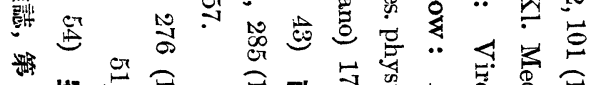

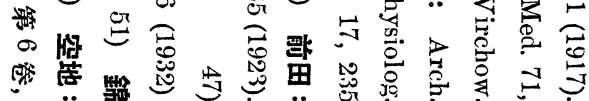


hemmende Wirkung der Ovarilaflüssigkeit war, verglichen mit der des Pelanins schwächer und ungleichmässiger, da die Konzentration der spezifischen Substanzen der Ovarialflüttigkeit je nach dem Zustande der Ovarialfunktion verschieden war.

3) Schilddrüse, Nebenniere, Pancreas und Thymusdrüse führten zu fast keinen nennenswerten Veränderungen. (Autoreferat.)

\section{Über den Einfluss von Thyroxin und Insulin auf das Blutbbild der Kaninchen mit unterbundenen Ernährungsgefässen des Knochenmarkes.}

Von

Dr. H. Imai.

(Aus der I. Med. Klinik der Kaiserl. Univers. zu Kyoto in Japan. Direktor : Prof. Dr. K. Tsuji)

Der Verfasser untersuchte den Einfluss von Thyroxin und Insulin auf das Blutbild normaler Kaninchen und das von solchen mit den unterbundenen Aa, nutriciae femoris, tibiae, fibulae, humeri und radio-ulnae.

Die Resultate waren wie folgt:

1) Die Injektion des Thyroxins führte bei den normalen Tieren zur Vermehrung der Thrombocyten, Erythrocyten, Reticulocyten und granulierten Leucocyten sowie zur Verminderung der gesamten Leucocyten und Iymphocyten.

2) Bei den Tieren mit unterbundenen Ernährungsgefässen kam es durch das Thyroxin nicht zur Vermehrung der Thrombocyten, Erythrocyten, Reticulocyten und granulierten Leucocyten.

3) Die Injektion des Insulins führte bei den normalen Tieren zur Vermehrung der Reticulocyten, der gesamten und granulierten Leucocyten und zur Verminderung der Thrombocyten, Erythorocyten 
und Lymphocyten.

4) Bei den Tieren mit unterbundenen Ernährungsgefässen kam es durch das Insulin zur Vermehrung der gesamten und granulierten Leucocyten und zur Verminderung der Thrombocyten, Erythrocyten, Reticulocyten und Lymphocyten.

(Autoreferat.)

\title{
Über den Einfluss von Adrenalin und einigen anderen Substanzen auf die blutbildende Funktion des Knochenmarkes.
}

\author{
Von \\ Dr. H. Imai. \\ (Aus der I. Med. Klinik der Kaiserl. Univers. zu Kyoto in Japan. \\ Direktor : Prof. Dr. K. Tsuji)
}

Der Verfasser untersuchte den Einfluss verschiedener Substanzen (Adrenalin, Histamin, Bariumchlorid und Thyroxin) auf die blutbildende Funktion des Knochenmarkes des isolierten durchströmten Kaninchenfemurs.

Die Resultate waren wie folgt:

1) Die Anzahl der Blutkörperchen in der ausströmenden Flüssigkeit war während der zweiten Stunde nach dem Beginn der Durchströmung fast konstant.

2) Adrenalin führte zur Zunahme der Leukocyten- und Erythrocytenzahl in der auströmenden Flüssigkeit. Auf die nachfolgende zweite Adrenalininjektion kam es wieder zur Vermehrung der Blutkörperchen.

3) Histamin verringerte die aus dem Knochenmark strömende Flüssigkeit so stark wie Adrenalin, vermehrte aber nicht die Blutkorperchen in der ausströmenden Flüssigkeit. Wurde jedoch Adrenalin nach dem Histamin injiziert, so kam es zur Vermehrung der Blutkörperchen.

4) Bariumchlorid veränderte die Blutkörperchenzahlen in der 